\title{
Impaired expression of testicular androgen receptor and collagen fibers in the testis of diabetic rats under HAART: the role of Hypoxis hemerocallidea
}

\author{
Onanuga O. Ismail ${ }^{1,2}$, Jegede A. Isaac ${ }^{1,3}$, Offor Ugochukwu ${ }^{1}$, Ogedengbe O. Oluwatosin ${ }^{1}$, \\ Peter I. Aniekan ${ }^{1}$, Naidu C.S. Edwin', Azu O. Onyemaechi' ${ }^{1,4}$ \\ ${ }^{1}$ Discipline of Clinical Anatomy, School of Laboratory Medicine and Medical Sciences, \\ Nelson R. Mandela School of Medicine, University of KwaZulu-Natal, Durban, South Africa \\ ${ }^{2}$ Department of Anatomy, Faculty of Biomedical Sciences, Kampala International University, \\ Dar es salaam, Tanzania \\ ${ }^{3}$ Department of Anatomy, Faculty of Basic Medical Sciences, College of Health Sciences, \\ Ladoke Akintola University of Technology, Ogbomoso, Nigeria \\ ${ }^{4}$ Department of Anatomy, School of Medicine, Windhoek, University of Namibia, Namibia
}

\begin{abstract}
Introduction. Wide spectrum of alterations associated with highly active antiretroviral therapy (HAART) has been reported. The current study aimed at evaluating the role of Hypoxis hemerocallidea $(\mathrm{HH})$ aqueous extract on the testosterone levels, expression of androgen receptors and collagen fibers in the testes of streptozotocin-nicotinamide-induced diabetic rats under HAART regimen.

Material and methods. Sixty two adult male Sprague-Dawley rats $(189.0 \pm 4.5 \mathrm{~g})$ were divided into eight groups ( 8 animals in each treatment groups and 6 rats in the control group). Diabetes was induced by a single intraperitoneal injection of nicotinamide $(110 \mathrm{mg} / \mathrm{kg} \mathrm{bw})$ followed by streptozotocin $(45 \mathrm{mg} / \mathrm{kg} \mathrm{bw})$ and the animals were then subjected to various treatments with HAART, HH extract or melatonin. At the end of the experiment, blood samples were collected to measure serum testosterone levels. Testes were fixed in buffered formaldehyde and paraffin processed. The expression of androgen receptor (AR) was assessed by immunohistochemistry and collagen fibers were visualized by Masson trichrome staining.

Results. Serum testosterone level was drastically $(\mathrm{p}<0.0001)$ reduced in all rats with induced diabetes. In the testis of diabetic rats increased collagen fibers deposition with varying derangements in germinal epithelium of spermatogenic layers were observed. Intertubular hemorrhages and absence of spermatozoa were also noted in the testes of diabetic rats subjected to HAART. Reduced immunoexpression of ARs was found in the nuclei of Sertoli cells and the cytoplasm of spermatogonia and spermatocytes in III-IV stages of the seminiferous epithelium cycle of diabetic animals treated with different dosages of $\mathrm{HH}$ alone and those treated with HAART concomitantly with melatonin and $\mathrm{HH}$. The expression of ARs was almost negative in the testes of rats treated with HAART alone. Conclusions. Concomitant treatment of rats with aqueous HH extract during the HAART did not change serum testosterone level nor mitigate the altered expression of collagen fibers and androgen receptor resulting from STZ-nicotinamide-induced diabetes. Therefore, anti-diabetic properties of Hypoxis extract require further investigation. (Folia Histochemica et Cytobiologica 2017, Vol. 55, No. 3, 149-158)
\end{abstract}

Key words: HAART; testis; diabetes; androgen receptors; collagen fibers; Hypoxis hemerocallidea; rat 


\section{Introduction}

The incidence and prevalence of diabetes co-morbidity in people living with human immunodeficiency virus (HIV) and acquired immune deficiency syndrome (AIDS) (PLWHAs) is becoming alarming in the populace. A total of 1,724 cases of diabetes were identified among 41,068 PLWHAs [1]. The reported prevalence rates ranged from $2.85 \%$ to $14.9 \%$ [2]. The high level of variability in the reported incidence and prevalence rates of diabetes co-morbidity observed [3] is paralleled by a wide spectrum of metabolic alterations associated with highly active antiretroviral therapy (HAART). This includes changes in glucose homeostasis and fat redistribution $[4,5]$ even in the face of enhanced quality of life outcomes associated with HAART [6].

The involvement of HIV and HAART in inducing endocrine or metabolic dysfunction has been reported [7] with consequential increase in morbidity and mortality due to cardiovascular diseases [8]. HIV infection, especially in the advanced stages, is associated with an augmented and sustained pro-inflammatory state. It activates macrophages to actively secrete pro-inflammatory cytokines like tumor necrosis factor- $\alpha$ (TNF- $\alpha$ ) and interleukin-1 (IL-1) [9]. These cytokines cause an alteration in the hypothalamus-pituitary-adrenal/thyroid/gonadal axes, which directly affects hormonal secretion at the cellular level [10]. The strongest relationship with diabetes was exposure to stavudine, while treatment with zidovudine and didanosine were also associated with an increased risk of diabetes $[11,12]$. This constellation of abnormalities called antiretroviral-associated diabetes is consistent with the clinical picture of type 2 diabetes mellitus (T2DM), rather than type 1 diabetes mellitus (T1DM) [13].

Diabetes mellitus (DM) is mainly presented with hyperglycemia, consequent of defects in insulin secretion, insulin action, or both. The most prevalent form of DM is T2DM, comprising up to $95 \%$ of all diagnosed diabetic individuals [14]. T2DM induces metabolic alterations, disrupting the endocrine system, with a subsequent dysfunction of the hypothalamus-pituitary-testicles (HPT) axis [15]. This may result in impairment of the male reproductive health. Although not all diabetic men are infertile, evidences strongly associate T2DM with high prevalence of male subfertility/infertility [16] with associated reduction in birth rates [17]. Consequently, the disturbing increase in the number of diabetic men in reproductive age as well as the multiple molecular mechanisms and pathways that are affected by DM with substantial effects on male reproductive function $[18,19]$.
The testes comprises of heterogeneous cell population, including somatic and germ cells. Testicular cells present unique metabolic characteristics, in part due to the existence of the blood-testis barrier. The Sertoli cells (SCs) are responsible for the production of metabolic precursors essential for germ cells development [20]. These cells show a "Warburg-like effect" metabolism [21], using the external glucose to produce lactate, which is the preferred substrate of developing germ cells [22].

The main function of the testis is the production of spermatozoa in the process of spermatogenesis. This complex process is precisely regulated by androgens, although, estrogens have also been shown to be involved [23, 24]. Androgens are steroid hormones primarily involved in the establishment of sexual maturation at puberty, and in maintenance of the male reproductive function, spermatogenesis and sexual behavior during adult life [25]. Many studies have proved that not only androgens have important functions in the adult male reproductive organ, but also estrogen and its receptors are essential for normal fertility in the male. Androgen and estrogen exert their cellular effects via steroid receptors (ARs and ERs, respectively) of the nuclear receptor superfamily and act as ligand-dependent transcription factors [26]. After the binding of androgens, ARs undergo a conformational change, dimerization, translocation to the cell nucleus and binding to specific DNA sequence, thus modulating expression of target genes [27].

Exogenous insulin and other medications can control many aspects of diabetes, numerous complications affecting longevity and quality of life [28]. HIV/AIDS treatment nowadays includes chronic and metabolic complications of the disease, and the adverse effects associated with its treatments. The high cost of insulin and HAART-associated toxicities necessitates the need for safer and less demanding adjuvant. Plant-based adjuvant has the potential to fill this need. The search for herbal remedies has continued to grow due to its accessibility, relatively low cost and a perceived effectiveness. Consequently, there is wide spread of consumption of herbal products, including Hypoxis hemerocallidea $(\mathrm{HH})$ for the management of HIV/AIDS either as complimentary or alternative medicine [29].

Hypoxis hemerocallidea (African potato) belongs to the genus of the family Hypoxidaceae [30] and is freely distributed in five provinces of South Africa, including KwaZulu-Natal. Anecdotal use of $H H$ predates many generations [31] especially its traditional utilization for the treatment of various ailments related to the urogenital system [32]. However, the popularity of this plant rose tremendously following the increased 
burden from the scourge of HIV/AIDS and its treatment as PLWHAs relied upon the corm for immune boosting potentials. The Hypoxis corm is noted for the occurrence of a hypoxide (a powerful antioxidant component) which is a secondary metabolite of the plant [32] that is hydrolyzed into rooperol in the large intestine [33]. Pharmacokinetic studies have indicated that rooperol can be found in feces, and metabolites are found in the serum and urine as its glycosides, sulfates, mixed glucuronides and sulfuronides [29]. The glycoside has low toxicity and the corm containing it is also used as food [30] and has been well used for traditional and pharmaceutical purposes [31].

With increasing interest in the use of phytosterols, also a phytochemical component of Hypoxis, for the reduction of serum cholesterol and immune boosting, there has been a resultant increase in scientific investigations [34] surrounding these benefits. This is paralleled by the accessibility of commercially available herbal medicines containing sterols with Hypoxis extract enrichments claimed to be efficacious against a variety of diseases.

Studies from our laboratory [35], however, indicate that the perceived positive benefits of extracts from Hypoxis require further scientific investigations in view of the negative hepatotoxic indices emanating from our animal model. Whilst PLWHAs continue to patronize Hypoxis product for various reasons, there is a need to understand potential interactions and benefits following antiretroviral therapy in diabetic comorbid. Therefore, this study was designed to evaluate the effects of the Hypoxis hemerocallidea on the testis of streptozotocin-nicotinamide-induced diabetic rats through immunopathological study, using both androgen receptors and collagen fibers as indicators of the testicular integrity.

\section{Material and methods}

Drugs and reagents. Nicotinamide, melatonin, lamivudine (3TC), zidovudine and nevirapine (Aspen) were purchased from Pharmed Ltd., Durban, South Africa. Monoclonal Anti-antibody kits (N-20, Santa Cruz Biotechnology, CA, USA), diaminobenzidine (DAB) and streptozotocin (Sigma-Aldrich, St. Louis, MO, USA) of analytical grade quality were purchased from Capital Lab Supplies, Durban, South Africa. Glucose strips (Bayer Contour TS, Basel, Switzerland) was purchased from local pharmacy.

Collection of plant material. Fresh corms of Hypoxis hemerocallidea were purchased from a local 'Muthi' in Umbilo Road, Durban, KwaZulu-Natal, between June and July, 2014. The corms were authenticated at the Department of
Life Science, Westville Campus, University of KwaZulu-Natal, Durban, South Africa.

Extraction of Hypoxis hemerocallidea. Hypoxis fresh corms were extracted according to the procedure of Ojewole [36]. They were washed with water, cut into smaller pieces, air dried at room temperature $\left(25-28^{\circ} \mathrm{C}\right)$ and ground into powdered form in a commercial blender. The milled corm was soaked in hot distilled water and extracted twice, on each occasion with 2.5 liters of hot distilled water (at $90-100^{\circ} \mathrm{C}$ ) for 12 hours. The combined extract soluble were concentrated to dryness under reduced pressure in a rotary evaporator at $70 \pm 1^{\circ} \mathrm{C}$. The resulting crude aqueous extract was freezedried, finally giving of a dark brown and powdery aqueous extract residue. Without any further purification, aliquot portions of the aqueous extract residue were weighed and dissolved in distilled water (at room temperature) for use on each day of our experiments.

Animals. Sixty two adult male Sprague-Dawley rats aged 9-10 weeks $(189.0 \pm 4.5 \mathrm{~g}$, mean \pm SEM $)$ were used for this study. The animals were maintained at the Animal House of the Biomedical Resources Unit, University of KwaZulu-Natal. The animals received humane care in accordance with the Principle of Laboratory Animal Care of the National Medical Research Council and the Guide for the Care and Use of Laboratory Animals of the National Academy of Sciences (National Institute of Health Guide, 1985). The study protocol was approved by the University of KwaZulu-Natal Animal Ethics Committee (Ethical clearance number: 056/15/Animals). All the rats were housed in well ventilated plastic cages having dimensions of $36 \mathrm{~cm}$ long $\times 24 \mathrm{~cm}$ wide $\times 15 \mathrm{~cm}$ high. They were maintained under standardized animal house conditions (temperature: $28-31^{\circ} \mathrm{C}$; light: approximately 12 hours natural light per day) and were fed with standard rat pellets from (Meadow feeds, a Division of Astral Operations Limited, Durban, South Africa) and given tap water ad libitum.

Experimental design. Diabetic animals $(n=56)$ were distributed into seven treatment groups: B-H with eight animals per group and the control group $(\mathrm{A}, \mathrm{n}=6)$ and treatment was administered as follows: group A received water as placebo (negative control vs. diabetic rats); group B served as diabetic control (positive control); group C received HAART cocktail (zidovudine, lamivudine and nevirapine), using the human therapeutic dose equivalents $(600 \mathrm{mg}, 300 \mathrm{mg}$ and $400 \mathrm{mg} /$ day, respectively), as adjusted for animal weight to obtain corresponding therapeutic doses for the rat model [37]; group D received $H H$ extract $(100 \mathrm{mg} / \mathrm{kg}$ bw); group E received $H H$ extract ( $200 \mathrm{mg} / \mathrm{kg} \mathrm{bw}$ ); group F received combined HAART cocktail and melatonin $(5 \mathrm{mg}$ ) $/ \mathrm{kg}$ bw); group $\mathrm{G}$ received combined HAART cocktail and 
$H H$ extract (100 mg/kg bw) and group $\mathrm{H}$ received combined HAART cocktail and $H H$ extract ( $200 \mathrm{mg} / \mathrm{kg}$ bw).

All substances were administered daily by oro-gastric gavage and the treatment lasted for 8 weeks.

Induction of type 2 diabetes mellitus (T2D). To induce type 2 diabetes mellitus animal model, rats were injected with single intraperitoneal dose of $110 \mathrm{mg} / \mathrm{kg}$ bw nicotinamide (Sigma-Aldrich) in physiological saline, and 15 minutes later, they were injected with $45 \mathrm{mg} / \mathrm{kg}$ bw of streptozotocin (Sigma-Aldrich) dissolved in citrate buffer ( $\mathrm{pH} 4.5$ ) before intraperitoneal injection [38]. The control groups received vehicle citrate buffer through the same route. Seven days later, blood glucose concentrations in STZ-induced diabetic rats greater than $20 \mathrm{mmol} / \mathrm{L}$ were considered as indices of diabetes.

Body mass measurements. Body weight (BW) changes of the animals were weekly recorded. BW of the rats was recorded on the first day before the commencement of the treatment (the initial body weight), thereafter weekly and on the last day shortly before animal sacrifice (final body mass). Testis weights (LW) were measured by an electronic balance (Mettle Toledo; Microsep (Pty) Ltd, Greifensee, Switzerland) after laparotomy. Values are expressed in grams for all weight measurements.

Material collection and analysis. Eight weeks post-treatment, all animals were sacrificed by exposure to Halothane ${ }^{\circledR}$ for 3 min via gas anesthetic chamber. Thereafter, blood samples were collected by cardiac puncture into pre-cooled heparinized tubes and centrifuged in a desktop centrifuge model 90-1 (Jiangsu Zhangji Instruments Co., Beijng, China) for $15 \mathrm{~min}$ at 3000 revolutions per minute. The serum was decanted into Eppendorf tubes and stored at $-80^{\circ} \mathrm{C}$ for subsequent analysis. The testicles were excised, weighed and immediately fixed in $10 \%$ neutral-buffered formalin. After proper fixation, the tissues were dehydrated in graded series of alcohol, cleared in xylene and embedded in paraffin wax using a cassette.

Histochemical examination of testes. Testes were sectioned at $5 \mu \mathrm{m}$ thickness using Leica RM 2255 microtome and were stained with Masson trichrome (MT) for collagen fibers according to Drury and Wallington [39]. The stained slides were then coverslipped using DPX mounting glue directly over the tissue section, ensuring no air bubbles were trapped. Thereafter, the slides were left overnight to dry for examination under the light microscope. The sections were examined using a binocular microscope and image acquisition was done, using the Nikon Eclipse 80i (Nicon, Tokyo, Japan). An independent histopathologist blinded to the treatment groups reported on the qualitative assessments of the slides.

Immunohistochemistry. The Avidin Biotin Complex (ABC) method was used. Androgen receptor (AR) was localized using rabbit anti-AR (N-20, Santa Cruz Biotechnology,
CA, USA). Antigenic sites were retrieved using citric acid solution and pressure cooker. Peroxidases, protein and biotin blocks were done using hydrogen peroxide, avidin and biotin, respectively. BRCA 1 and 2 antibodies were diluted 1:100 and incubated on sections. These were followed by the biotinylated secondary antibody, streptavidin and DAB/ /substrate reaction according to Nasra [19].

In brief, formalin fixed and paraffin embedded tissues were sectioned on the rotary microtome and placed on the hot plate at $70^{\circ} \mathrm{C}$ for at least 1 hour. Sections were brought down to water by passing on 2 changes of xylene, then 3 changes of descending grades of alcohol and finally to water. Antigen retrieval was performed on the sections by heating them on a citric acid solution of $\mathrm{pH} 6.0$ using microwave at power 100 for 15 minutes. The sections were equilibrated gradually with cool water to displace the hot citric acid for at least $5 \mathrm{~min}$ for the section to cool. Peroxidase blockings were done on the sections by covering section with $3 \%$ hydrogen peroxide $\left(\mathrm{H}_{2} \mathrm{O}_{2}\right)$ for $15 \mathrm{~min}$. Sections were washed with phosphate-buffered saline (PBS) and protein blocking were performed using avidin for $15 \mathrm{~min}$. Sections were washed with PBS and endogenous biotins in tissue were blocked using biotin for $15 \mathrm{~min}$. After washing with PBS, sections were incubated with the respective diluted primary antibodies (BRCA1) antibody diluted 1:100 for 60 minutes. Excess antibodies were washed off with PBS and secondary antibodies (LINK) were applied on section for 15 minutes. Sections were washed and the (LABEL) which is the horseradish peroxidase (HRP) were applied on the sections for 15 minutes. A working DAB solution was made up by mixing 1 drop $(20 \mu)$ of the DAB chromogen to $1 \mathrm{~mL}$ of the DAB substrate. The working solution was applied on sections after washing off the HRP with PBS for at least 5 min. The brown reactions begin to appear at the moment especially for a positive target. Excess DAB solution and precipitate were washed off with water. Sections were counterstained with hematoxylin for at least $2 \mathrm{~min}$. Sections were then dehydrated in alcohol, cleared in xylene and mounted in DPX.

Cells with specific brown colors in the cytoplasm, cell membrane or nuclei depending on the antigenic sites are considered to be positive. The hematoxylin-stained cells without any form of brown colors were scored negative. Non-specific binding/brown artifacts on cells and connective tissue are disregarded. For testicular cells, Sertoli cells were characterized by their large irregularly shaped nuclei on the basal layer of the seminiferous epithelium; myoid cells by their elongated nuclei around the periphery of the tubule; and Leydig cells by their round nuclei in the interstitial tissue. Assessment for androgen receptors was performed according to the following semi-quantitative scale: $(-)$ negative; $(+)$ weakly positive; $(++)$ positive; and $(+++)$ strongly positive [40].

Measurement of serum testosterone concentration. Testosterone was determined in duplicate, using the Testosterone 
Enzyme Immunoassay kit (Assay Design Inc., Ann Arbour, MI, USA) according to the manufacturer's instruction.

Statistical analysis. All continuous variables were collected, analyzed and expressed as mean \pm standard deviation (SD). Statistical comparison of the differences between the control and experimental groups was performed with GraphPad InStat Software (version 6.00, GraphPad Software, San Diego, CA, USA), using one-way analysis of variance (ANOVA) followed by Turkey-Kramer multiple comparison test. $\mathrm{P}<0.05$ was considered statistically significant.

\section{Results}

\section{Mortality}

One animal died in the course of the experiment in the diabetic group treated with HAART.

\section{Food and fluid intake and weight changes}

Diabetic animals exhibited many symptoms commonly associated with diabetes (e.g. polyuria, polydipsia and diarrhea). Food intake was not different, but a significantly ( $\mathrm{p}<0.001$ ) higher fluid intake was observed in all the diabetic groups compared with the negative control group (data not shown). The final body mass of rats in all groups were higher than the initial weight. Percentage change in body weight of all groups was significantly ( $p<0.001$ ) lower in groups $\mathrm{G}$ and $\mathrm{H}$ when compared with negative control (group A). Similarly, there were significant decline in body mass of rats treated with HAART + melatonin $(\mathrm{p}<0.0001)$ (Table 1).

\section{Serum concentrations of testosterone}

Serum testosterone levels of the diabetic animals in groups $(\mathrm{B}, \mathrm{C}$ through $\mathrm{H})$ were significantly $(\mathrm{p}<0.0001)$ reduced compared with the normoglycemic control group (Table 2). The level of testosterone was not reversed by the administration of $H H$ compared with the normoglycemic and diabetic control groups ( $\mathrm{p}<0.001$ and $\mathrm{p}<0.001$, respectively; Table 2).

\section{Histopathological examination of testes}

Varying degree of collagen fibers deposition was observed in the testes of diabeticanimals (Suppl.Fig. 1B-H). The area percent showed unequal collagen distribution as compared with the normoglycemic control animals, which is presented with normal morphology with all generations of germ cells in the stages of the seminiferous epithelium cycle (Suppl. Fig. 1A). In addition, the testis of the diabetic control and all STZ-treated rats showed varying irregularities in the structure of seminiferous tubules, lined with disorganized germinal epithelium and the intervening interstitial connective tissue. This deformity is more pronounced in the animals treated with HAART alone, as many tubules were necrotized with denuded/detached spermatogenic cells from basal lamina (Suppl. Fig. 1C). In testicular sections of groups $\mathrm{D}$ and E, many tubules were extensively atrophied with only lining basement membrane remaining and interstitial spaces that were sparsely populated with cellular components (Suppl. Fig. 1D-E).

\section{The expression of androgen receptors in the testes of control and experimental rats}

Immunolocalization of ARs in the wall of seminiferous tubules of normoglycemic rat testis was found in the cytoplasm and nuclei of Sertoli cells. Expression of ARs was also observed in the nuclei of peritubular myoid and Leydig cells (Fig. 1A, Table 2). As shown in Figure $1 \mathrm{~B}-\mathrm{H}$, there was a change in the pattern of ARs

Table 1. Body and testis mass of control and experimental rats

\begin{tabular}{|c|c|c|c|c|c|c|}
\hline & Treatment & Initial body mass [g] & Final body mass [g] & Body mass change (\%) & Testis mass [g] & Testis/body mass \\
\hline A & Control & $173.8 \pm 9.2$ & $289.8 \pm 23.4$ & 66.7 & $3.1 \pm 0.2$ & 1.10 \\
\hline B & D-control & $209.1 \pm 14.2$ & $270.6 \pm 60.8$ & 29.4 & $3.0 \pm 0.3$ & 1.10 \\
\hline C & HAART & $213.3 \pm 14.3$ & $268.3 \pm 40.9$ & 25.8 & $3.2 \pm 0.4$ & 1.10 \\
\hline D & $\mathrm{HH}_{100}$ & $196.3 \pm 18.6$ & $280.5 \pm 53.7$ & 42.9 & $3.2 \pm 0.2$ & 1.10 \\
\hline $\mathbf{E}$ & $\mathrm{HH}_{200}$ & $187.6 \pm 20.7$ & $242.4 \pm 50.2$ & 29.2 & $3.3 \pm 0.4$ & 1.13 \\
\hline F & $\mathrm{HAART}+\mathrm{Mel}$ & $181.1 \pm 19.8$ & $231.3 \pm 59.1$ & 27.7 & $2.0 \pm 1.2^{\alpha \beta}$ & $0.80^{\alpha \beta}$ \\
\hline G & HAART $+\mathrm{HH}_{100}$ & $186.9 \pm 56.4$ & $214.3 \pm 26.4$ & $14.7^{\alpha}$ & $3.0 \pm 0.4$ & 1.14 \\
\hline H & HAART $+\mathrm{HH}_{200}$ & $186.8 \pm 17.5$ & $213.0 \pm 52.1$ & $14.1^{\alpha}$ & $2.8 \pm 0.5$ & 1.13 \\
\hline
\end{tabular}

Data are shown as the mean $\pm \mathrm{SD} ; \mathrm{p}<0.0001^{\alpha \beta} v s$. group $\mathrm{A}^{\alpha}$ and $\mathrm{p}<0.05$ vs. group $\mathrm{B}^{\beta}$ (Turkey-Kramer multiple range post-hoc test). Abbreviations: D-control — diabetic-control; HAART — highly active antiretroviral therapy; $\mathrm{HH}_{100}-$ Hypoxis hemerocallidea, $100 \mathrm{mg} / \mathrm{day} ; \mathrm{HH}_{200}-$ Hypoxis hemerocallidea $200 \mathrm{mg} / \mathrm{day}$; Mel — melatonin. 
Table 2. Serum testosterone concentrations and summary of receptor localization in the rat testis presented as intensity of immunostaining

\begin{tabular}{|c|c|c|c|c|c|c|}
\hline \multirow[t]{2}{*}{ Group } & \multirow[t]{2}{*}{ Treatment } & \multirow[t]{2}{*}{ Testosterone $[\mathrm{nmol} / \mathrm{L}]$} & \multicolumn{4}{|c|}{$\mathbf{A R}$} \\
\hline & & & Sertoli cells & Leydig cells & Myoid cells & Germ cells \\
\hline A & Control & $20.1 \pm 6.8$ & ++ & +++ & +++ & - \\
\hline B & D-control & $2.5 \pm 2.2^{\alpha}$ & + & + & + & - \\
\hline C & HAART-d & $6.5 \pm 6.3^{\alpha}$ & + & + & - & - \\
\hline D & $\mathrm{HH}_{100}$ & $4.6 \pm 2.3^{\alpha}$ & + & + & + & - \\
\hline $\mathbf{E}$ & $\mathrm{HH}_{200}$ & $2.4 \pm 2.7^{\alpha}$ & ++ & + & + & - \\
\hline $\mathbf{F}$ & HAART + Mel & $0.1 \pm 0.1^{\alpha \beta}$ & + & + & + & - \\
\hline $\mathbf{G}$ & $\mathrm{HAART}+\mathrm{HH}_{100}$ & $0.3 \pm 0.1^{\alpha \beta}$ & ++ & + & + & $+*$ \\
\hline $\mathbf{H}$ & HAART + HH200 & $0.4 \pm 0.2^{\alpha \beta}$ & ++ & ++ & + & $+^{*}$ \\
\hline
\end{tabular}

Data are shown as the mean $\pm \mathrm{SD} ; \mathrm{p}<0.0001^{\alpha \beta} v$ s. Group $\mathrm{A}^{\alpha}$ and $\mathrm{B}^{\beta}, \mathrm{p}<0.001$ s. Group $\mathrm{E}^{\beta}$ (Turkey-Kramer multiple range post-hoc test). Intensity of immunostaining scored as negative $(-)$, weak positive $(+)$, moderate positive $(++)$ or strong positive $(+++)$. "III/IV stages of the seminiferous epithelium cycle as defined by two independent observers. Abbreviations as for Table 1, AR — androgen receptor.

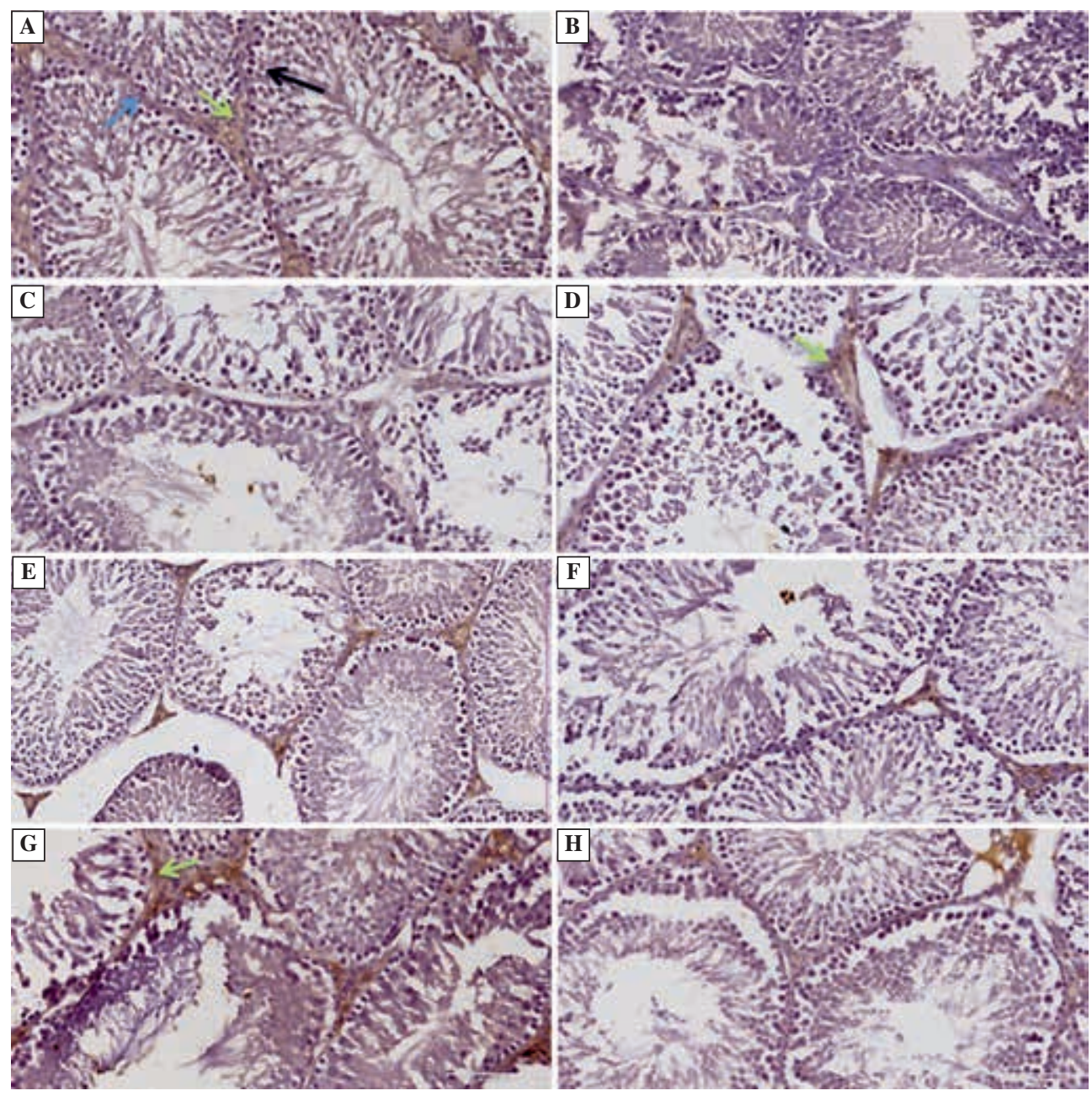

Figure 1. Immunoexpression of androgen receptor (AR) in the testis of control and experimental rats. A. Control group; B. Rat with streptozotocin-induced diabetes (diabetic group); C. Diabetic rats on HAART regimen; D. Diabetic rats treated with $100 \mathrm{mg} /$ day of $H H$; E. Diabetic rats treated with $200 \mathrm{mg} /$ day of $H H ; \mathbf{F}$. Diabetic rats on HAART treated with melatonin; G. Diabetic rats on HAART treated with $100 \mathrm{mg} /$ day of $H H$; H. Diabetic rats on HAART treated with $200 \mathrm{mg} / \mathrm{day}$ of $H H$. Symbols: black arrow — nuclei of Sertoli cell; blue arrows — myoid cells; green arrows — Leydig cells. Abbreviations as in the description of Table 1. 
expression in the testes of diabetic control and all $\mathrm{HH}$ alone, HAART + melatonin, $H H+$ HAART-treated animals (Table 2). The expression was almost negative in the testis of diabetic control (group B) and those treated with HAART alone (Fig. 1B-C). Positive reaction was present not only in the Sertoli cells, but also in the cytoplasm of spermatogonia and spermatocytes in III/IV stages of the seminiferous epithelium cycle of the animals treated with HAART concomitantly with Hypoxis of both dosages (Table 2). Germ cells of the other stages of the seminiferous epithelium cycle did not show immunoreactivity for AR. Expression of ARs was also observed in the nuclei of myoid cells and the nuclei of Leydig cells (Fig. 1A-B, Table 2). In control slides, no AR-positive cells were detected when the primary antibody was omitted.

\section{Discussion}

The use of medicinal herbs, a principal component of traditional medicine, predates the emergence of HIV/AIDS, and there is widespread consumption of herbal products for the management of HIV/AIDS either as complementary or alternative medicine [29].

The current study revealed that diabetic damage resulting from streptozotocin-nicotinamide-induction in the era of HAART can affect not only the morphology but also the expression of androgen receptors in the testis of rats. In addition, the examined serum testosterone level was significantly altered. HAART with $H H$ induced negative observational changes in the body weight of experimental animals, mostly marked in the diabetic + HAART + HH (100 and $200 \mathrm{mg} / \mathrm{kg}$ ) animals. While loss of weight may be associated with induction of diabetes, initiation of HAART may as well contribute to the low pace of weight gain due to other metabolic activities relative to lipid and sugar [41].

Diabetes mellitus is characterized by absolute or relative deficiencies in insulin secretion and/or insulin action associated with chronic hyperglycemia and disturbances of carbohydrate, lipid and protein metabolism. Testicular cells, specifically Sertoli cells (SCs), take up extracellular glucose via specific glucose transporters (GLUTs), which is then oxidized to pyruvate and promptly reduced to lactate by lactate dehydrogenase (LDH), with a concomitant oxidation of NADH. Once produced, lactate is exported through the monocarboxylate transporter 4 (MCT4) to the intratubular fluid to become available for the developing germ cells. Thus, SCs and germ cells establish a tight metabolic cooperation that is highly dependent on glucose uptake and lactate production $[22,42]$. From the physiological point of view the metabolism of carbohydrates, especially glucose, is vital for male reproductive health, so the maintenance of testicular glucose metabolism homeodynamics is of particular relevance; otherwise spermatogenesis is arrested [43]. Hence, the full enlightenment of testicular glucose metabolism and the molecular mechanisms that control it is of extreme importance, since alterations in these mechanisms may be the basis of male infertility [42].

While blood glucose levels remain elevated in this present study at the dosages used, previous reports [44] show that the methanolic extract of Hypoxis hemerocallidea at very high dose of $800 \mathrm{mg} / \mathrm{kg}$ and above was found to reduce blood glucose concentrations in normal and diabetic rats by $35 \%$ and $55 \%$, respectively, for few hours as compared with anti-diabetic effects of glibenclamide [44]. The associated physiological responses to diabetic states (including excessive loss of fluid with consequent weight loss) are reflected in our data, of which adjuvant $H H$ was unable to restore. This perhaps raises concern on the antihyperglycemic property or beneficial use of $\mathrm{HH}$ extracts by the indigenous communities for the treatment of adult-induced diabetes mellitus. Serum testosterone levels also remained diminished in all the diabetic rats. Reduced serum testosterone in diabetic rats was attributed in previous studies to neuroendocrine dysfunction and the absence of the stimulatory effect of insulin on the Leydig cells $[19,45]$.

In the present study, the seminiferous tubules basement membrane of the experimental groups showed thickening, which was similar to Santoro et al. report [46]. More so, observation of the seminiferous tubules with detached, disorganized germ cells and dislocation of spermatozoa to positions that are closely related to the basement membrane with decreased seminiferous epithelial height in group administered with HAART were also observed. As earlier reported, the results may be due to the rapid disruption of Sertoli-germ cells interactions due to disturbance of normal supportive function of Sertoli cells as a result to exposure to some drugs and injurious toxicants [47]. The physical interaction ultimately leads to sloughing of the germ cells from the seminiferous epithelium.

Data from this study showed that diabetes and HAART created extensive structural changes in the seminiferous tubules of the animals which were neither ameliorated with Hypoxis nor melatonin treatment. The reduction in spermatogenic cells seen is similar to atrophic seminiferous tubules with denuded sperm cells which are all consequences of a diabetic pathology [48]. Derangements in the process of spermatogenesis seen in diabetic conditions have been previously documented $[45,49]$ and this applies also 
to the testicular disruption [50]. Diabetes is known to alter basement membrane thickness which ultimately causes declines in sperm production (count) and morphology of the tubules [51]. Explanation for this is understandable by the fact that due to inadequate insulin production, Sertoli and Leydig cell functions deteriorate in addition to weakening of spermatogenesis consequent on reduced FSH levels [52].

Androgen receptor (AR) is a member of a large family of ligand-activated nuclear receptors and is highly expressed in the testes, particularly in Sertoli cells [53]. Sertoli cells are thought to be the major cellular target for the testosterone signaling that is required to support male germ cell development and survival [54]. In the current study, ARs are localized to the nuclei of Sertoli cells, peritubular myoid cells, Leydig cells and the cytoplasm of spermatogonia and spermatocytes in III/IV stages of the seminiferous epithelium cycle of the animals treated with HAART concomitantly with Hypoxis of both dosages. This finding is in accordance with previous ones where absence of AR immunoexpression in germ cells and intense staining in Sertoli cells (SCAR) was thought to be the major cellular target for the testosterone signaling that is required to support male germ cell development and survival [53,54]. Male mice lacking SCARs were reported to be associated with infertility, as spermatogenesis rarely progress beyond meiosis [55, 56]. Several spermatogenic disorders are associated with impaired androgenic stimulation of Sertoli cells; thus, low levels of the AR are likely to be involved in spermatogenic disorders [57] or incorrect androgen-sensitive course of spermatogenesis [58].

Testosterone also plays important role in the final maturation of Sertoli cells [59], and both testosterone and FSH have additive effects on SCAR expression [57]. As reported in this study, testosterone level was significantly reduced in all HAART and $H H$ treated animals. More so, rather than FSH stimulation, AR expression has been shown to be primarily dependent on the testosterone level [60], as AR knockout affects the ability of Sertoli cells to support maturing germ cells, resulting in spermatogenesis arrest before the first meiotic division and during the transition from round to elongated spermatids, causing progressive loss of fertility [55].

Furthermore, the administration of melatonin results in a rapid rise in blood melatonin concentrations and due to its lipophilic and hydrophilic properties [48], it passes rapidly through all biological membranes and enters the cells and their subcellular compartments. This is an advantage for melatonin over some other antioxidants that penetrate cells more slowly. However, we observed that melatonin administered at the dose $(5 \mathrm{mg} / \mathrm{kg})$ in this protocol did not mitigate the testicular dysfunction observed. This probably may be due to melatonin-HAART interaction which suppresses its efficacy as an antioxidant.

In addition, it was observed that the diabetic control animals as well as all the treated animals showed more of cytoplasmic instead of nuclear AR expression. The findings could be explained in the light of previous studies - in the presence of androgens AR is normally localized in the nucleus, while in the absence of androgens the receptors migrate from the nucleus back into normal cytoplasm [61]. Therefore, alterations in normal AR expression in these cells would be an indicator of the hormonal status of the cells [62].

In conclusion, our results further suggest the inability of Hypoxis or melatonin to ameliorate testicular dysfunction observed in diabetic rats. Further investigation on alternate dosages is on-going in our laboratory to ascertain the claimed anti-hyperglycemic property of the Hypoxis, which will be essential to provide new insights into the effects of HAART-associated T2DM on testicular integrity and male fertility.

\section{Acknowledgements}

We acknowledge the award of operational funds by the College of Health Science, University of KwaZulu-Natal to Postgraduate student Onanuga I.O. Technical support from Dr. Sanil Singh and Dr. Linda Bester of Biomedical Research Unit, University of KwaZulu-Natal is acknowledged. "This work is based on the research supported in part by the National Research Foundation" (NRF) of South Africa for the grant, Unique Grant No U99053 to the senior author.

\section{Conflict of interest}

\section{No conflicts of interest.}

\section{References}

1. Brown TT, Cole SR, Li X, et al. Antiretroviral therapy and the prevalence and incidence of diabetes mellitus in the multicenter AIDS cohort study. Arch Intern Med. 2005; 165(10): 1179-1184, doi: 10.1001/archinte.165.10.1179, indexed in Pubmed: 15911733.

2. NigatuHaregu T, Oldenburg B, Setswe G, et al. Magnitude of diabetes comorbidity among people living with HIV: A systematic review. Int J Diabet Res. 2013; 1(5): 81-86, doi: 10.5923/j.diabetes.20120105.02.

3. Nigatu T, Oldenburg B, Elliott J, et al. The incidence of cardiovascular disease, cancer and type 2 diabetes comorbidities in HIV infection: A systematic review. J Nurs Educ Pract. 2013; 3(7): 58-67, doi: 10.5430/jnep.v3n7p58.

4. Calza L, Manfredi R, Chiodo F. Insulin resistance and diabetes mellitus in HIV-infected patients receiving antiretroviral therapy. Metab Syndr Relat Disord. 2004; 2(4): 241-250, doi: 10.1089/met.2004.2.241, indexed in Pubmed: 18370693. 
5. Grinspoon S. Mechanisms and strategies for insulin resistance in acquired immune deficiency syndrome. Clin Infect Dis. 2003; 37(Suppl 2): S85-S90, doi: 10.1086/375885, indexed in Pubmed: 12942379.

6. Lohse N, Hansen ABEg, Pedersen G, et al. Survival of persons with and without HIV infection in Denmark, 1995-2005. Ann Intern Med. 2007; 146(2): 87-95, indexed in Pubmed: 17227932.

7. Anuurad E, Semrad A, Berglund L. Human immunodeficiency virus and highly active antiretroviral therapy-associated metabolic disorders and risk factors for cardiovascular disease. Metab Syndr Relat Disord. 2009; 7(5): 401-410, doi: 10.1089/ met.2008.0096, indexed in Pubmed: 19355810.

8. Grinspoon S, Carr A. Cardiovascular risk and body-fat abnormalities in HIV-infected adults. N Engl J Med. 2005; 352(1): 48-62, doi: 10.1056/NEJMra041811, indexed in Pubmed: 15635112 .

9. Kibirige D, Ssekitoleko R. Endocrine and metabolic abnormalities among HIV-infected patients: a current review. Int J STD AIDS. 2013; 24(8): 603-611, doi: 10.1177/0956462413479895, indexed in Pubmed: 23970578.

10. Zapanti E, Terzidis K, Chrousos G. Dysfunction of the hypothalamic-pituitary-adrenal axis in HIV infection and disease. Hormones (Athens). 2008; 7(3): 205-216, indexed in Pubmed: 18694859

11. De Wit S, Sabin CA, Weber R, et al. Data Collection on Adverse Events of Anti-HIV Drugs (D:A:D) study. Incidence and risk factors for new-onset diabetes in HIV-infected patients: the Data Collection on Adverse Events of Anti-HIV Drugs (D:A:D) study. Diabetes Care. 2008; 31(6): 1224-1229, doi: 10.2337/dc07-2013, indexed in Pubmed: 18268071.

12. Kalra S, Kalra B, Agrawal N, et al. Understanding diabetes in patients with HIV/AIDS. Diabetol Metab Syndr. 2011; 3(1): 2 , doi: 10.1186/1758-5996-3-2, indexed in Pubmed: 21232158.

13. Dagogo-Jack S. HIV therapy and diabetes risk. Diabetes Care. 2008; 31(6): 1267-1268, doi: 10.2337/dc08-0459.

14. American Diabetes Association. Diagnosis and classification of diabetes mellitus. Diabetes Care. 2011; 35(Suppl 1): S64-S71, doi: $10.2337 / \mathrm{dc} 12-\mathrm{s} 064$.

15. Rato L, Alves MG, Dias TR, et al. Testicular metabolic reprogramming in neonatal streptozotocin-induced type 2 diabetic rats impairs glycolytic flux and promotes glycogen synthesis. J Diabetes Res. 2015; 2015: 973142, doi: 10.1155/2015/973142, indexed in Pubmed: 26064993.

16. La Vignera S, Condorelli R, Vicari E, et al. Diabetes mellitus and sperm parameters. J Androl. 2012; 33(2): 145-153, doi: 10.2164/jandrol.111.013193, indexed in Pubmed: 21474785.

17. Hamilton BE, Hoyert DL, Martin JA, et al. Annual summary of vital statistics: 2010-2011. Pediatrics. 2013; 131(3): 548-558, doi: 10.1542/peds.2012-3769, indexed in Pubmed: 23400611.

18. Alves MG, Martins AD, Rato L, et al. Molecular mechanisms beyond glucose transport in diabetes-related male infertility. Biochim Biophys Acta. 2013; 1832(5): 626-635, doi: 10.1016/j. bbadis.2013.01.011, indexed in Pubmed: 23348098.

19. Ayuob NN, Murad HAS, Ali SS. Impaired expression of sex hormone receptors in male reproductive organs of diabetic rat in response to oral antidiabetic drugs. Folia Histochem Cytobiol. 2015; 53(1): 35-48, doi: 10.5603/FHC.a2015.0005, indexed in Pubmed: 25765091.

20. Gillot I, Jehl-Pietri C, Gounon P, et al. Germ cells and fatty acids induce translocation of CD36 scavenger receptor to the plasma membrane of Sertoli cells. J Cell Sci. 2005; 118(Pt 14): 3027-3035, doi: 10.1242/jcs.02430, indexed in Pubmed: 15972317.
21. Oliveira PF, Martins AD, Moreira AC, et al. The Warburg effect revisited--lesson from the Sertoli cell. Med Res Rev. 2015; 35(1): 126-151, doi: 10.1002/med.21325, indexed in Pubmed: 25043918.

22. Rato L, Alves MG, Socorro S, et al. Metabolic modulation induced by oestradiol and DHT in immature rat Sertoli cells cultured in vitro. Biosci Rep. 2012; 32(1): 61-69, doi: 10.1042/ BSR20110030, indexed in Pubmed: 21671886.

23. Carreau S, Bouraima-Lelong H, Delalande C. Role of estrogens in spermatogenesis. Front Biosci (Elite Ed). 2012; 4: 1-11, indexed in Pubmed: 22201851.

24. Pilutin A, Misiakiewicz-Has K, Kolasa A, et al. The immunoexpression of androgen receptor, estrogen receptors alpha and beta, vanilloid type 1 receptor and cytochrome p450 aromatase in rats testis chronically treated with letrozole, an aromatase inhibitor. Folia Histochem Cytobiol. 2014; 52(3): 206-217, doi: 10.5603/FHC.2014.0024, indexed in Pubmed: 25308736.

25. Patrão MT, Silva EJR, Avellar MC. Androgens and the male reproductive tract: an overview of classical roles and current perspectives. Arq Bras Endocrinol Metabol. 2009; 53(8): 934-945, indexed in Pubmed: 20126845.

26. Lee HR, Kim TH, Choi KC. Functions and physiological roles of two types of estrogen receptors, $\mathrm{ER} \alpha$ and $\mathrm{ER} \beta$, identified by estrogen receptor knockout mouse. Lab Anim Res. 2012; 28(2): 71-76, doi: 10.5625/lar.2012.28.2.71, indexed in Pubmed: 22787479.

27. Yong EL. Androgen receptor gene and male infertility. Hum Reprod Update. 2003; 9(1): 1-7, doi: 10.1093/humupd/ dmg003.

28. Ceriello A. Oxidative stress and glycemic regulation. Metabolism. 2000; 49(2): 27-29, doi: 10.1016/s0026-0495(00)80082-7.

29. Fasinu PS, Bouic PJ, Rosenkranz B. The inhibitory activity of the extracts of popular medicinal herbs on CYP1A2, 2C9, $2 \mathrm{C} 19$ and $3 \mathrm{~A} 4$ and the implications for herb-drug interaction. Afr J Tradit Complement Altern Med. 2014; 11(4): 54-61, doi: 10.4314/ajtcam.v11i4.9., indexed in Pubmed: 25392581.

30. Drewes $\mathrm{S}$, Hall A, Learmonth $\mathrm{R}$, et al. Isolation of hypoxoside from hypoxis rooperi and synthesis of (E)-1,5-bis(3,4 -dimethoxyphenyl)pent-4-en-1-yne. Phytochemistry. 1984; 23(6): 1313-1316, doi: 10.1016/s0031-9422(00)80449-5.

31. Awad AB, Fink CS. Phytosterols as anticancer dietary components: evidence and mechanism of action. J Nutr. 2000; 130(9): 2127-2130, indexed in Pubmed: 10958802.

32. Nair VDP, Dairam A, Agbonon A, et al. Investigation of the antioxidant activity of African potato (Hypoxis hemerocallidea). J Agric Food Chem. 2007; 55(5): 1707-1711, doi: 10.1021/jf0619838, indexed in Pubmed: 17295502.

33. Laporta O, Perezfons L, Mallavia R, et al. Isolation, characterization and antioxidant capacity assessment of the bioactive compounds derived from Hypoxis rooperi corm extract (African potato). Food Chemistry. 2007; 101(4): 1425-1437, doi: 10.1016/j.foodchem.2006.03.051.

34. Moreau RA, Whitaker BD, Hicks KB. Phytosterols, phytostanols, and their conjugates in foods: structural diversity, quantitative analysis, and health-promoting uses. Prog Lipid Res. 2002; 41(6): 457-500, indexed in Pubmed: 12169300.

35. Azu O, Jegede A, Ugochukwu O, et al. Hepatic histomorphological and biochemical changes following highly active antiretroviral therapy in an experimental animal model: Does Hypoxis hemerocallidea exacerbate hepatic injury? Toxicology Reports. 2016; 3: 114-122, doi: 10.1016/j.toxrep.2015.12.013. 
36. Ojewole JAO, Awe EO, Nyinawumuntu A. Antidiarrhoeal activity of Hypoxis hemerocallidea Fisch. \& C. A. Mey. (Hypoxidaceae) Corm ('African potato') aqueous extract in rodents. Phytother Res. 2009; 23(7): 965-971, doi: 10.1002/ ptr.2732, indexed in Pubmed: 19140171.

37. Umar RA, Hassan SW, Ladan MJ, et al. Adverse effects associated with antiretroviral therapy drugs (nevirapuine, lamivudine and stavudine) to albino rats: implication for management of patients with HIV/AIDS. Asian J Biochem. 2000; 3: 19-25.

38. Mojani MS, Sarmadi VH, Vellasamy S, et al. Evaluation of metabolic and immunological changes in streptozotocin-nicotinamide induced diabetic rats. Cell Immunol. 2014; 289(12): 145-149, doi: $10.1016 /$ j.cellimm.2014.04.004, indexed in Pubmed: 24791700.

39. Drury RAB, Wallington EA. Carleton's Histological Technique. 5th ed. Oxford University Press, Oxford New York 1980.

40. Al-Azemi M, Omu FE, Kehinde EO, et al. Lithium protects against toxic effects of cadmium in the rat testes. J Assist Reprod Genet. 2010; 27(8): 469-476, doi: 10.1007/s10815-0109426-3, indexed in Pubmed: 20455018.

41. Deveaud C, Beauvoit B, Reynaud A, et al. Site-specific reduction of oxidative and lipid metabolism in adipose tissue of 3'-azido-3'-deoxythymidine-treated rats. Antimicrob Agents Chemother. 2007; 51(2): 583-590, doi: 10.1128/AAC.0107806, indexed in Pubmed: 17158934.

42. Rato L, Alves MG, Dias TR, et al. High-energy diets may induce a pre-diabetic state altering testicular glycolytic metabolic profile and male reproductive parameters. Andrology. 2013; 1(3): 495-504, doi: 10.1111/j.2047-2927.2013.00071.x, indexed in Pubmed: 23495257.

43. Rato L, Alves MG, Socorro S, et al. Metabolic regulation is important for spermatogenesis. Nat Rev Urol. 2012; 9(6): 330-338, doi: 10.1038/nrurol.2012.77, indexed in Pubmed: 22549313.

44. Zibula SMX, Ojewole JAO. Hypoglycaemic Effect of Hypoxis hemerocallidea Corm Methanolic Extract in Rats. Med J Islamic Acad Sci. 2000; 13: 75-78.

45. Ballester J, Muñoz MC, Domínguez J, et al. Insulin-dependent diabetes affects testicular function by FSH- and $\mathrm{LH}$-linked mechanisms. J Androl. 2004; 25(5): 706-719, doi: 10.1002/ j.1939-4640.2004.tb02845.x, indexed in Pubmed: 15292100.

46. Santoro G, Romeo C, Impellizzeri P, et al. A morphometric and ultrastructural study of the changes in the lamina propria in adolescents with varicocele. BJU Int. 1999; 83(7): 828-832, doi: 10.1046/j.1464-410x.1999.00023.x, indexed in Pubmed: 10368207.

47. Richburg JH. The relevance of spontaneous- and chemically-induced alterations in testicular germ cell apoptosis to toxicology. Toxicol Lett. 2000; 112-113: 79-86, doi: 10.1016/ s0378-4274(99)00253-2., indexed in Pubmed: 10720715.

48. Guneli E, Tugyan K, Ozturk H, et al. Effect of melatonin on testicular damage in streptozotocin-induced diabetes rats. Eur Surg Res. 2008; 40(4): 354-360, doi: 10.1159/000118032, indexed in Pubmed: 18303272.

49. Kianifard D, Sadrkhanlou RA, Hasanzadeh S. The ultrastructural changes of the Sertoli and Leydig cells following streptozotocin induced diabetes. Iran J Basic Med Sci. 2012; 15(1): 623-635, indexed in Pubmed: 23493249.

50. Azu OO, Naidu ECS, Naidu JS, et al. Testicular histomorphologic and stereological alterations following short-term treatment with highly active antiretroviral drugs (HAART) in an experimental animal model. Andrology. 2014; 2(5): 772-779, doi: 10.1111/j.2047-2927.2014.00233.x, indexed in Pubmed: 24919589.

51. Richardson LL, Kleinman HK, Dym M. Altered basement membrane synthesis in the testis after tissue injury. J Androl. 1998; 19(2): 145-155, indexed in Pubmed: 9570737.

52. Kiyanifard D, Hassanzadeh SH, Sadrkhanlo RA, et al. Study of changes Structure seminiferouse tubule and hormone changes gonadotropin diabetic rats. Medical J Med. 2010; 22: 239-248.

53. Kato Y, Shiraishi K, Matsuyama H. Expression of testicular androgen receptor in non-obstructive azoospermia and its change after hormonal therapy. Andrology. 2014; 2(5): 734-740, doi: 10.1111/j.2047-2927.2014.00240.x, indexed in Pubmed: 24919724.

54. Griswold MD. Perspective on the function of Sertoli cells. In: Skinner MK, Griswold MD. ed. In: Sertoli Cell Biology. Elsevier Science, San Diego, CA 2005: 15-18.

55. Chang $\mathrm{C}$, Chen YT, Yeh SD, et al. Infertility with defective spermatogenesis and hypotestosteronemia in male mice lacking the androgen receptor in Sertoli cells. Proc Natl Acad Sci U S A. 2004; 101(18): 6876-6881, doi: 10.1073/ pnas.0307306101, indexed in Pubmed: 15107499.

56. O'Shaughnessy PJ, Verhoeven G, De Gendt K, et al. Direct action through the sertoli cells is essential for androgen stimulation of spermatogenesis. Endocrinology. 2010; 151(5): 2343-2348, doi: 10.1210/en.2009-1333, indexed in Pubmed: 20228170.

57. Verhoeven G, Willems A, Denolet E, et al. Androgens and spermatogenesis: lessons from transgenic mouse models. Philos Trans R Soc Lond B Biol Sci. 2010; 365(1546): 1537-1556, doi: 10.1098/rstb.2009.0117, indexed in Pubmed: 20403868.

58. Kolasa-Wolosiuk A, Misiakiewicz-Has K, Baranowska-Bosiacka I, et al. Androgen levels and apoptosis in the testis during postnatal development of finasteride-treated male rat offspring. Folia Histochem Cytobiol. 2015; 53(3): 236-248, doi: 10.5603/fhc.a2015.0025, indexed in Pubmed: 26377331.

59. Sharpe RM. Sertoli cell endocrinology and signal transduction: androgen regulation. In: Skinner MK, Griswold MD. ed. Sertoli Cell Biology. Elsevier Science, San Diego, CA 2005: 199-216.

60. Hill CM, Anway MD, Zirkin BR, et al. Intratesticular androgen levels, androgen receptor localization, and androgen receptor expression in adult rat Sertoli cells. Biol Reprod. 2004; 71(4): 1348-1358, doi: 10.1095/biolreprod.104.029249, indexed in Pubmed: 15215201.

61. Trybek G, Kolasa A, Marchlewicz M, et al. Immunolocalization of androgen receptor in the epididymis of rats with dihydrotestosterone deficiency. Reprod Biol. 2005; 5(3): 291-301, indexed in Pubmed: 16372046.

62. Zaya R, Hennick C, Pearl CA. In vitro expression of androgen and estrogen receptors in prepubertal and adult rat epididymis. Gen Comp Endocrinol. 2012; 178(3): 573-586, doi: 10.1016/j. ygcen.2012.07.004, indexed in Pubmed: 22809666.

Submitted: 11 May, 2017

Accepted after reviews: 16 September, 2017 Available as AoP: 29 September, 2017 